\title{
COMPARATIVE STUDY BETWEEN FAT AND PERICHONDRIUM GRAFT MYRINGOPLASTY
}

\author{
Magdy A. Fattah*., Adly Tantawy*. Waleed Ibrahim, **, and MohamedEl- Nemr.* \\ ENT department, Zagazig University* and Audiology Unit ENT department Zagazig University**
}

\begin{abstract}
Introduction: Longstanding tympanic membrane perforation may cause hearing loss and middle ear infection even if they are small in size. The purpose of myringoplasty is to repair such perforations and thus to improve hearing and eliminate the susceptibility to middle ear infection.

Methodology: This study was included 40 patients with dry central tympanic membrane perforation, not associated with ossicular pathology, retraction pocket or cholesteatoma showing conductive hearing loss with an air bone gab not exceeding $30 \mathrm{dBHL}$ in the studied ear. Patients were divided into 2 groups (group I and group II) 20 patients who have undergone fat myringoplasty and 20 patients who have undergone perichondrium tympanoplasty. Each group was subdivided into 2 subgroups (A and B) according to size of perforation. Audiological evaluation was done pre and postoperative.

Results: In fat myringoplasty, the success rate was $50 \%$ with success rate of $80 \%$ in group I A ( $<4 \mathrm{~mm})$ and a success rate of $20 \%$ in group IB $(>4 \mathrm{~mm})$. In perichondrium tympanoplasty, the overall success rate was about $80 \%$ with only 4 failed cases from 20 cases.

It was found that there was improvement of hearing in group IA ranging from $7.5-10 \mathrm{~dB}$ with a mean of $9 \pm 1$ while in group IIA; there was improvement of hearing ranging from $5-20 \mathrm{~dB}$ with a mean of $10 \pm 6.5$. There was no significant difference as regards improvement of hearing $(\mathrm{P}=0.67)$. While in group IB, the 2 successful cases showed improvement of hearing ranging of about $10 \mathrm{~dB}$ while in group IIB; there was improvement of hearing ranging from $7.5-20 \mathrm{~dB}$ with a mean of $12 \pm 5 \mathrm{~dB}$. So, in large perforation, there was no significant difference between the studies groups $(\mathrm{P}=0.6)$.

Conclusion: Fat graft myringoplasty is a reliable technique with shorter duration less operative care. Success rate is higher for perichondrium graft. Hearing improvement is not significantly different between both groups.
\end{abstract}

Key words: fat graft- Perichondrium tympanoplast.

\section{INTRODUCTION}

L ongstanding tympanic membrane perforation may cause hearing loss and middle ear infection even if they are small in size. Further, the patients have to observe water restriction. The purpose of myringoplasty is to repair such perforations and thus to improve hearing and eliminate the susceptibility to middle ear infection (1).

Various tissues and materials have been used with a variety of surgical procedures and success rate in myringoplasty operations ${ }^{(2)}$. Perichondrium is one of the most preferred grafting materials in myringoplasty operations due to its anatomic proximity, translucency, and suppleness. Moreover, being mesodermal in origin, it is free from the possibility of post operative cholesteatoma ${ }^{(3)}$.

Ringenberg successfully used adipose tissue-fat to repair small tympanic membrane perforations in 1962 $2^{(4)}$. Mitchell et al., (1997) used fat in 342 children to close small tympanic membrane perforation achieving $92 \%$ success rate (5). Fat plug myringoplasty is a simple technique to repair a small central tympanic membrane perforation. It is easy, quick and cost effective with minimal morbidity ${ }^{(6)}$.

The simplicity and ease make fat plug myringoplasty suitable for outpatient procedures.
As there is no disturbance to middle ear structures, there is a negligible risk of any iatrogenic otological trauma making this procedure very safe even for bilateral repairs. This also includes minimal disruption of daily life for patients. Patients who fail to respond with this procedure can undergo proper tympanoplasty at later life ${ }^{(6)}$.

\section{Patients and methods:}

This study was conducted on 40 patients selected among patients attending outpatient Clinic, Otorhinolaryngology Department, Zagazig University Hospitals.

IRB approval was optained on March 2012 number 1377/25/3/2012.

Cases selection:

Patients included in the study fulfilled these criteria:

- Dry central tympanic membrane perforation, not associated with ossicular pathology, retraction pocket or cholesteatoma.

Pure tone audiometry showing conductive hearing loss with an air bone gab not exceeding $30 \mathrm{~dB}$ in the studied ear.

Cases with previous history of myringoplasty or with uncontrolled systemic disease were not included in the study. All ears were dry for at least 6 weeks before the operation. 
The study was carried out on two randomly selected groups:

\section{Group I:}

It was composed of 20 patients who have undergone fat myringoplasty. It was divided into 2 subgroups (each composed of 10 cases) according to the size of the perforation by measuring its diameter, by means of suction ear tubes with diameter of known values:

Subgroup A: the size of the perforation was small with its diameter up to $4 \mathrm{~mm}$.

Subgroup B: the size of the perforation was large with its diameter more than $4 \mathrm{~mm}$.

\section{Group II:}

It was composed of 20 patients who have undergone perichondrium tympanoplasty. It was divided into 2 subgroups; each composed of 10 cases according to the size of the perforation by measuring its diameter by means of suction ear tubes with diameter of known values:

Subgroup A: the size of the perforation was small with its diameter up to $4 \mathrm{~mm}$.

Subgroup B: the size of the perforation was large with its diameter more than $4 \mathrm{~mm}$

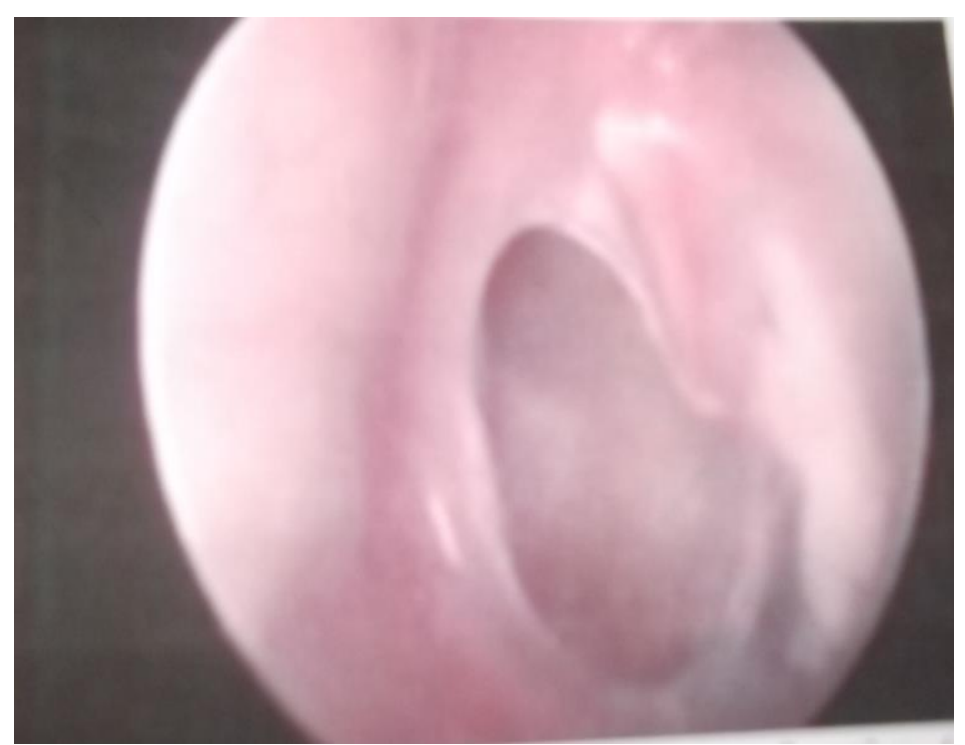

Figure (1): A large tympanic membrane perforation preoperatively (subgroup B).

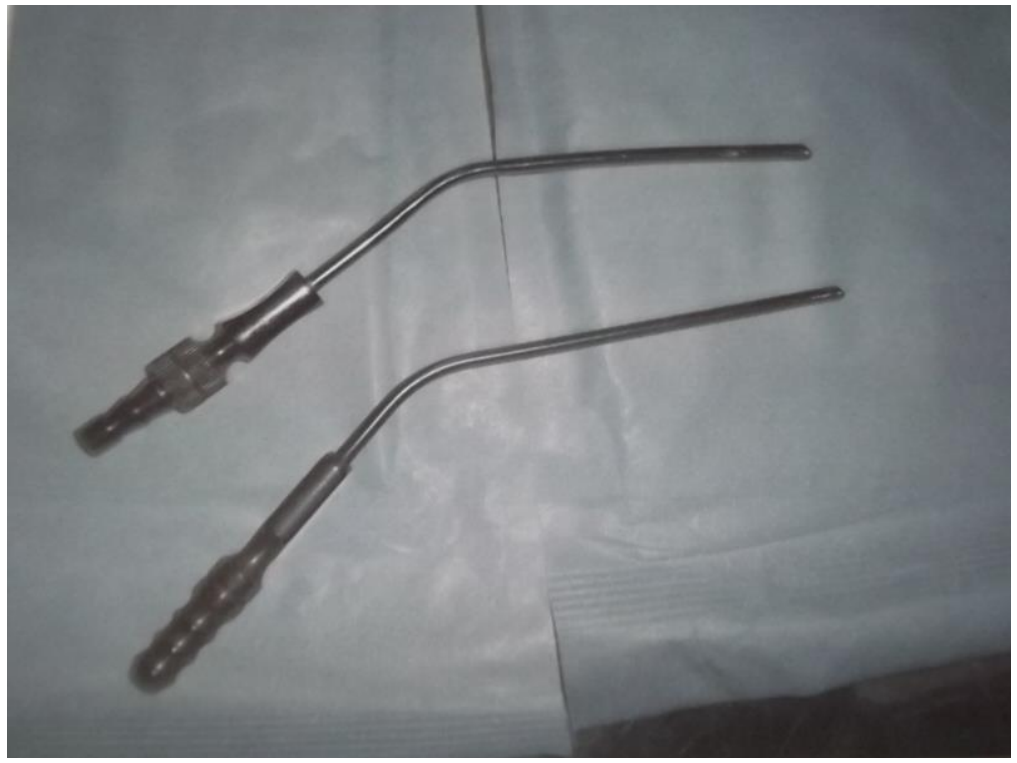

Figure (2): Suction ear tubes. 


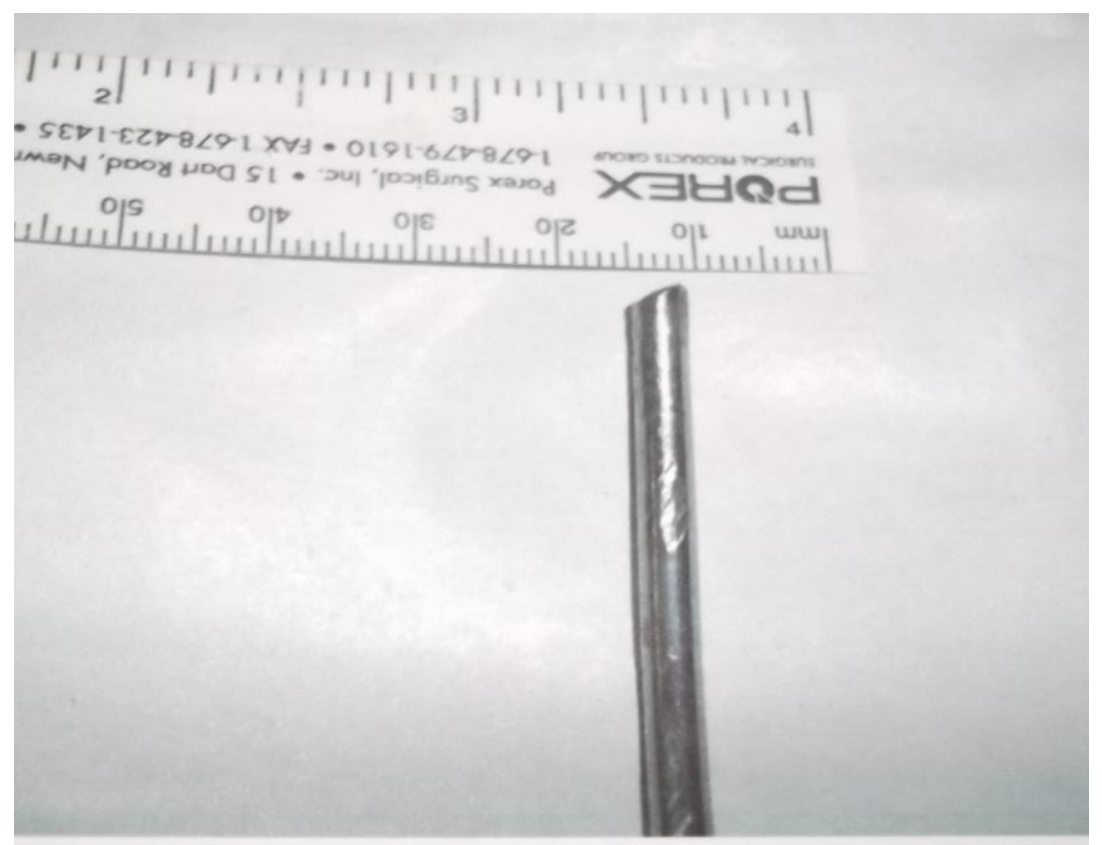

Figure (3): Suction ear tube $6 \mathrm{ml}$.

\section{Preoperative evaluation of the patients:}

1- History taking:

(1) Personal history: name, age, sex, occupation and marital state.

(2) Complaint: aural discharge, hearing loss and tinnitus.

(3) Present history: all symptoms were analyzed regarding time of onset, duration, course, presence or absence of aggravating factors.

(4) Past history: to exclude previous attempts at myringoplasty in the studied ears and the presence of associated uncontrolled systemic disease.

2- Otological examination:

- Otoscopy was done to determine the size and site of perforation.

- Tuning fork Rinne' and Weber tests (using 512 and $1024 \mathrm{~Hz}$ tuning forks) to determine the presence of conductive hearing loss.

3- Audiological evaluation:

- Pure tone audiometry using double channel audiometer (Orbiter two channelpure tone and speech audiometer 922 version 2) where Air-Bone Gap (ABG) is measured by calculating the mean of difference between bone conduction and air conduction at frequencies $(500,1000,2000$ and $4000 \mathrm{~Hz})$.

- Speech discrimination.

- Tympanometry using tympanometer (amplaid 719). To assess Eustachian tube function.

mastoid:

$$
\text { 4- Preoperative plain } \mathrm{X} \text { - ray }
$$

All patients had a preoperative plain Xray mastoid to exclude any mastoid pathology.
Operative procedure:

All cases were operated under general anesthesia either due to patient preference or due to the need for abdominal fat graft in other cases.

\section{1- $\quad$ Fat myringoplasty:}

Ear lobule fat was harvested through infiltration of the ear lobule with $1 \%$ xylocaine with $1 / 100,000$ adrenaline. A small incision was made along the posterior aspect of the ear lobule. The fat was harvested by sharp dissecting scissors taking care not to perforate the anterior skin. The size of fat graft was twice the size of the perforation. The ear lobule incision was closed with 4-0 interrupted silk sutures.

Abdominal fat graft was done in cases with large perforations. The graft was harvested through a $1 \mathrm{~cm}$ transverse incision in the left lower quadrant of anterior abdominal wall by sharp dissection. The incision was closed in two layers.

The fat plug in either case was put in sterile saline until the time of its application.

The ear was draped in a sterile technique. The endomeatal approach via an ear speculum was used. The edges of the perforation were excised under the operation microscope using a sharp needle and cup forceps to de-epithelialize the edge to encourage haling or migration of the mucosal layer and epithelium across the graft.

The middle ear was then packed with a single piece of gelfoam. The fat plug was placed through the perforation into the middle ear and then pulled back partially through the perforation to ensure eversion of the perforation edge. The fat plug is thus positioned so that it fills the depth of middle ear with a small part lateral to the 
tympanic membrane in an hourglass fashion (Ayache etal., 2003).

The ear canal was packed with gelfoam moistened in antibiotic solution. A standard ear dressing was applied.

2- Perichondrium tympanoplasty:

The Perichondrium is harvested from the tragus or concha of the auricle. From the tragus, a skin incision was made just medial to its summit, on its posterior surface. The skin and subcutaneous tissues are dissected off the Perichondrium on its posterior aspect to delineate the extent of the required graft. The perichondrium is then incised on the posterior aspect of the tragus just medial to the summit; the sheet of perichondrium is elevated.

The margins of the graft are then divided, the graft is then removed and donor site is closed.

From the concha, post auricular incision was done and the skin and subcutaneous tissue were dissected off the perichondrium at the region of the concha bowel. A piece of perichondrium is harvested and it should be $2 \mathrm{~mm}$ longer then the perforation diameter.

A tympanomeatal flap is created by making an incision at the 6 O'clock position in the ear and bringing this laterally in the canal to just before the junction of the bony and cartilaginous part of the ear canal. Another incision is begun just lateral and slightly posterior to the short process of the malleus. Again, the incision is brought laterally before turning inferiorly to connect with the other incision. This creates an apron-shaped tympanomeatal flap.

First, fresh of the perforation with removal of thickened tympanic membrane and associated tympanosclerosis. Then, elevation of the flap should be performed carefully and delicately. After inspection of the middle ear, the remnants of the tympanic membrane was grafted using underlay technique medial to the handle of malleus and immediately adjacent to the incus to reconstruct the entire tympanic membrane.

The external auditory canal was packed by 2 packs soaked with antibiotic cream. The postauricular wound was closed in two layers.

\section{Postoperative follow up:}

The outer pack was removed one week after while the inner pack was removed 3 weeks after operation. The sutures were removed one week after operation. Return visits were scheduled at one week, 3 weeks, 9 weeks, 3 months and 6 months postoperatively.

Assessment of the results:

All patients were followed-up postoperatively as regards:

a. Clinically: the patients were examined in each of the follow-up visits regarding:

i. Graft taking.

ii.Drum mobility.

iii. Tuning fork tests.

b. Audiologically after 3 months.

i.Pure tone audiometry.

ii.Tympanometry and acoustic reflexes.

\section{Statistical analysis:}

Data were entered checked and analyzed using Epi-Info version 6 and SPP for windows version 8 .

\section{RESULTS}

Demographics of the study group showed that, subgroup IA with age range from 18-28 years with a mean of $23 \pm 4.1$ while in subgroup IIA ranged from 12-55 years with a mean of 29.6 13. While subgroup IB age ranged from 12-35 with a mean of $21.4 \pm 8.2$ while in subgroup IIB age ranged from $19-35$ years with a mean of $26.5 \pm$ 5.9. There was no significant difference between the studied groups regarding age (Table, 1 ).

Table (1): Age distribution of the study group.

\begin{tabular}{llllll}
\hline & IA & IIA & IB & IIB & P. \\
\hline $\begin{array}{lllll}\text { Age (years) } \\
\text { Mean+ SD }\end{array}$ & $23 \pm 4.1$ & $29.6 \pm 13$ & $21.4 \pm 8.2$ & $26.5 \pm 5.9$ & \\
\hline Range & $18-28$ & $12-55$ & $12-35$ & $19-35$ & 0.15 \\
\hline
\end{tabular}

Air bone gap in subgroup IA ranged from 15-20 dB HL with a mean of $17.5 \pm 2.3$ while in subgroup IIA it ranged from 15- $25 \mathrm{~dB}$ HL with a mean of $19 \pm 2.1$. There was no statistically significant difference between the studied groups as regards ABG (Table, 2). 
Table (2): Air bone gap in subgroups IA and IIA before tympanoplasty.

\begin{tabular}{clll}
\hline & Before & t. & P \\
\hline \multirow{2}{*}{ IA } & $\begin{array}{l}17.5 \pm 2.3 \\
(15-20)\end{array}$ & & \\
\multirow{2}{*}{ IIA } & $\begin{array}{l}19.5 \pm 2.1 \\
(15-25)\end{array}$ & & 0.15 \\
\hline
\end{tabular}

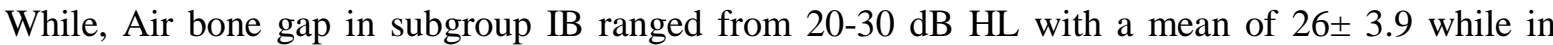
subgroup IIB it ranged from $10-30 \mathrm{~dB}$ HL with a mean of $21 \pm 7$. And there was no statistically significant difference between the studied groups as regards ABG also (Table, 3 ).

Table (3): Comparison of air bone gap in group IB and IIB before tympanoplasty.

\begin{tabular}{clcc}
\hline & Before & t. & P \\
\hline \multirow{2}{*}{ IB } & $26 \pm 3.9$ & & \\
& $(20-30)$ & \multirow{2}{*}{1.96} & 0.06 \\
\hline \multirow{2}{*}{ IIB } & $\begin{array}{l}21 \pm 7 \\
(10-30)\end{array}$ & & \\
\hline
\end{tabular}

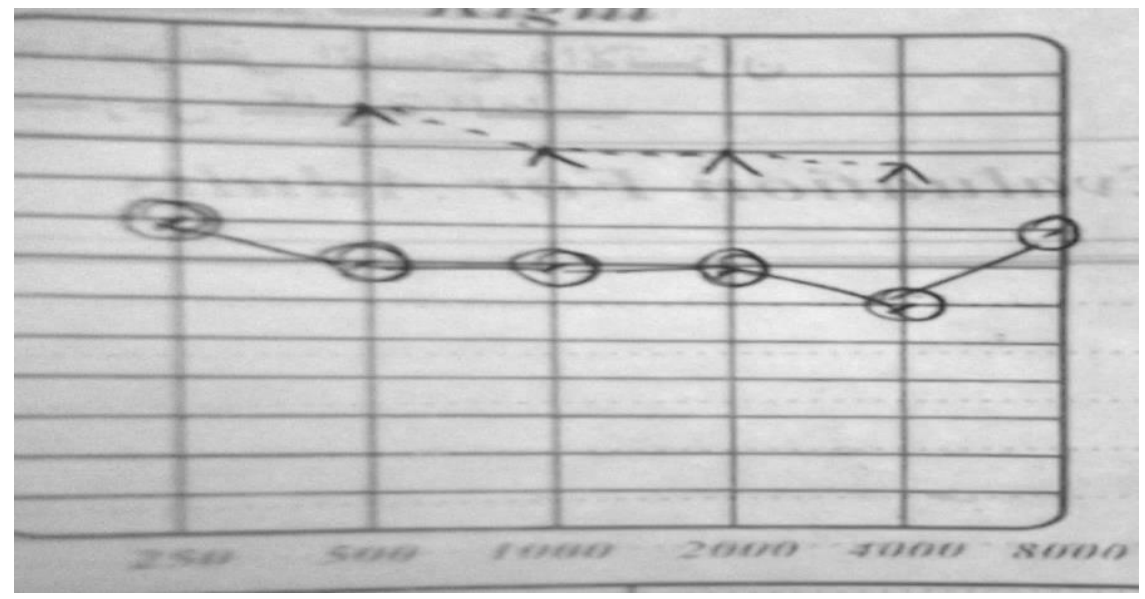

Figure (4): showing air bone gab pre-operatively in a case with large perforation.

Regarding the fate of the graft in group (A) both subgroups had $80 \%$ success rate with no significant difference. On the other hand, in group B $20 \%$ success rate in subgroup (I) in comparison to $80 \%$ in subgroup (II) which was proved significant (Tables, 4 and 5).

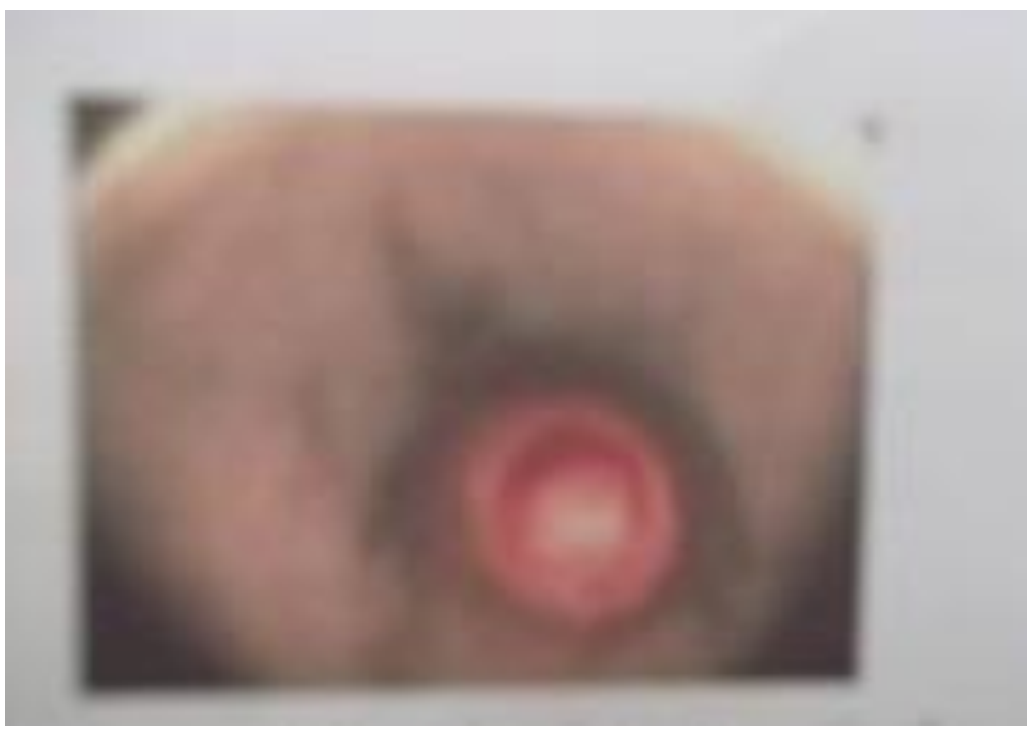

Figure (5): showing fat plug intra-operatively. 
Table (4): Comparison between the two studied groups regarding the fate of the graft take.

\begin{tabular}{|c|c|c|c|c|c|c|}
\hline & \multicolumn{2}{|c|}{ IA } & \multicolumn{2}{|c|}{ IIA } & \multirow[t]{2}{*}{$\mathrm{X}^{2}$} & \multirow[t]{2}{*}{$\mathrm{P}$} \\
\hline & No. & $\%$ & No. & $\%$ & & \\
\hline Success & 8 & 80 & 8 & 80 & 0 & 1 \\
\hline Failed & 2 & 20 & 2 & 20 & & \\
\hline
\end{tabular}

Table (5): Comparison between the two studied groups regarding the fate of the graft take.

\begin{tabular}{|c|c|c|c|c|c|c|}
\hline & \multicolumn{2}{|c|}{ IB } & \multicolumn{2}{|c|}{ IIB } & \multirow[t]{2}{*}{$\mathrm{X}^{2}$} & \multirow[t]{2}{*}{$\mathrm{P}$} \\
\hline & No. & $\%$ & No. & $\%$ & & \\
\hline Success & 2 & 20 & 8 & 80 & 7.2 & $0.007 *$ \\
\hline Failed & 8 & 80 & 2 & 20 & & \\
\hline
\end{tabular}

Post operative ABG was studied and revealed in subgroup IA successful cases had ABG range of 5-

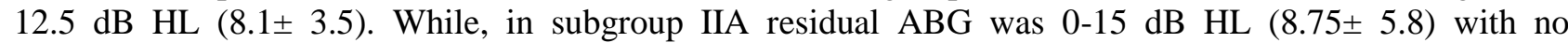
statistically significant difference (Table, 6). Also, ABG in subgroups IB and IIB in successful cases, showed non significant difference (Table, 7).

Table (6): Comparison of air bone gap in group IA and IIA postoperative.
After
t.
$\mathrm{P}$

$\begin{array}{ll} & 8.1 \pm 3.5 \\ \text { IA } & (5-12.5)\end{array}$

\begin{tabular}{llll}
\hline IIA & 0.26 & 0.79 \\
& $\begin{array}{l}8.75 \pm 5.8 \\
(0-15)\end{array}$ & & \\
\hline
\end{tabular}

Table (7): Comparison of air bone gap in group IB and IIB postoperative.
After
t.
$\mathrm{P}$

IB

15

$\begin{array}{ll} & 9.4 \pm 8.9 \\ & (0-20)\end{array}$




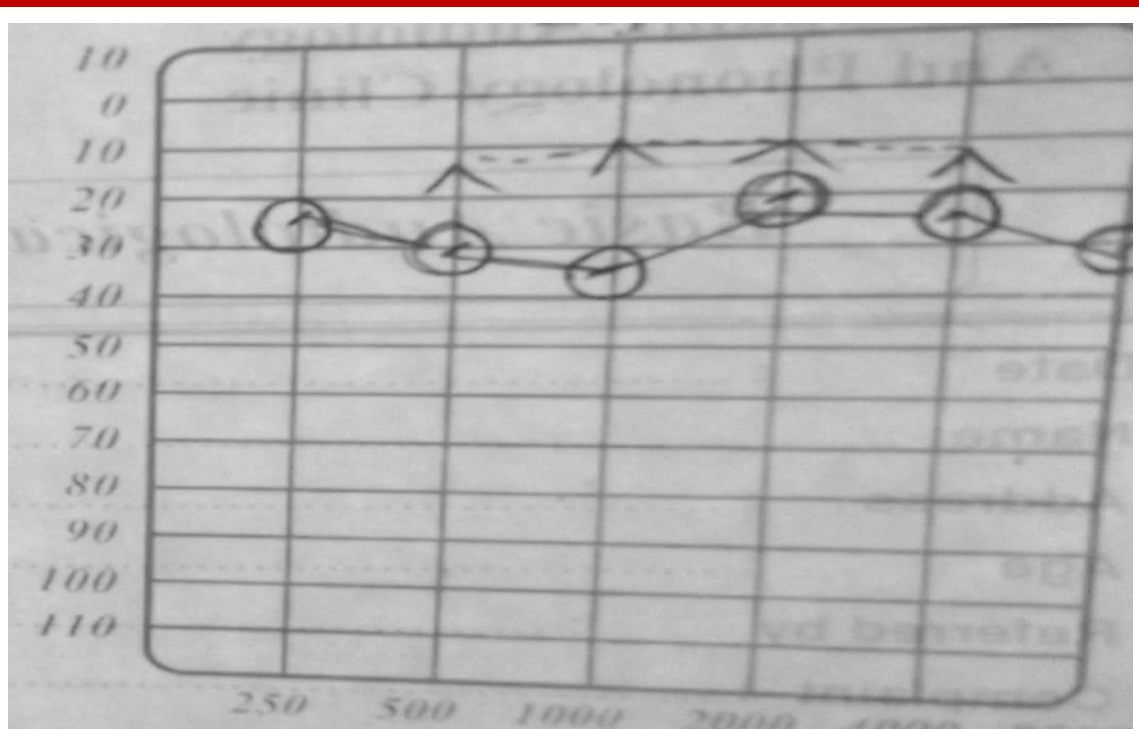

Figure (6): showing the same patient's air bone gab postoperatively.

Comparing the size of perforation and success rate we found in patients with perichondrium no significant difference as regards size of perforation (Table, 8) while fat graft showed statistically significant difference between small and larger sized perforation as regards graft take (Table, 9).

Table (8): relation between the size of perforation and rate of graft take in Perichondrium graft.

\begin{tabular}{lllllll}
\hline & \multicolumn{2}{c}{ IIA } & \multicolumn{2}{c}{ IIB } & $X^{2}$ & P \\
\cline { 2 - 5 } & No. & $\%$ & No. & $\%$ & \\
\hline Success & 8 & 80 & 8 & 80 & 0 & 1 \\
\hline Failed & 2 & 20 & 2 & 20 & & \\
\hline
\end{tabular}

Table (9): relation between the size of perforation and rate of graft take in fat graft.

\begin{tabular}{|c|c|c|c|c|c|c|}
\hline & \multicolumn{2}{|c|}{ IA } & \multicolumn{2}{|c|}{ IB } & \multirow[t]{2}{*}{$\mathrm{X}^{2}$} & \multirow[t]{2}{*}{$\mathrm{P}$} \\
\hline & No. & $\%$ & No. & $\%$ & & \\
\hline Success & 8 & 80 & 2 & 20 & 7.2 & $0.007^{*}$ \\
\hline Failed & 2 & 20 & 8 & 80 & & \\
\hline
\end{tabular}

As regards improvement of haring, there was no significant difference regarding improvement of hearing either in those with fat graft or perichondrium graft between those with small perforation or larger perforation (Table, 10).

Table (10): improvement of hearing between subgroups of either type of grafts.

\begin{tabular}{llllll}
\hline & Perforation size & & t. & P \\
\cline { 2 - 5 } Graft type & IA & IIA & & \multirow{2}{*}{0.42} & 0.67 \\
& $9 \pm 1$ & $10 \pm 6.5$ & & \\
\cline { 2 - 6 } & $(7.5-10)$ & $(5-20)$ & & \\
& IB & IIB & 0.53 & 0.6 \\
& 10 & $(7.5-20)$ & & \\
\hline
\end{tabular}

Finally comparing success rate between group I and II and comparing improvement of hearing between the two groups.

Table (11): success rate between group I and II.

\begin{tabular}{llllllll}
\hline & \multicolumn{3}{c}{ I } & \multicolumn{5}{c}{ II } & X & P \\
\cline { 2 - 6 } & No. & & $\%$ & No. & & $\%$ & \\
\hline Success & 10 & 50 & 16 & 80 & 3.96 & 0.046 \\
\hline Failed & 10 & 50 & 4 & 20 & & \\
\hline
\end{tabular}


Table (12): improvement of hearing between groups I and II.

\begin{tabular}{|c|c|c|c|c|c|}
\hline & I & $\overline{\text { II }}$ & & & $\bar{P}$ \\
\hline $\begin{array}{l}\text { Improvement of } \\
\text { hearing }\end{array}$ & $\begin{array}{l}9.5 \pm 4.5 \\
(5-20)\end{array}$ & $\begin{array}{l}11.6 \pm 4.5 \\
(7.5-20)\end{array}$ & 1.14 & 0.26 & \\
\hline
\end{tabular}

\section{DISCUSSION}

The present study was carried out to compare between the effectiveness of fat myringoplasty and perichondrium tympanoplasty in small and large tympanic membrane perforations.

In this study age was found to have no effect on the success rate there was no significant difference as regards age (table, $\mathbf{1})$. This agreed with Deddens et al. (1993) ${ }^{(7)}$, who found no significant difference in outcome as regards to patients' age. In a series of approximately 342 patients in which a success rate of $92 \%$ was achieved, Mitchell et al. (1997) ${ }^{(5)}$, concluded that there is no relationship between patients' age and postoperative results. Also, Ayache et al. (2003) ${ }^{(8)}$ did not observe any predictive role with regard to age.

Pure tone audiometry was one of the selection criteria in the present study. Cases selection was limited to an ABG of no more than $35 \mathrm{~dB}$ to ensure free ossicular mobility in the studied ears as middle ear exploration is not attempted in the fat plug technique.

As regard the graft take, in fat myringoplasty, the success rate was $50 \%$ with success rate of $80 \%$ in group I A $(<4 \mathrm{~mm})$ and a success rate of $20 \%$ in group IB $(>4 \mathrm{~mm})$. This was coincident with series by Konstantinidis et al. (2010) ${ }^{(9)}$ who have used fat with success rate of 79 and $86.3 \%$ respectively. But, these studies were carried out on small perforations not exceeding $50 \%$ of tympanic membrane surface. While this study was not limited by size and the success rate of it in small perforations was $80 \%$ which was coincident with results of other studies.

Failure rate in the other studies was not mentioned, while failure in this study in group IA was due to that the anterior wall of the external auditory canal presented a posterior bulging and prevented a complete identification of the perforations anterior rim resulting in an incomplete contact between the tympanic remnant and the aft graft and the occurrence of upper respiratory tract infection in another case 2 weeks postoperatively.

In perichondrium tympanoplasty, the overall success rate was about $80 \%$ with only 4 failed cases from 20 cases. In Dabholkar et al.
(2007) ${ }^{(3)}$ study, the success rate also was $80 \%$. Reijnen and Kuijpers (1971) ${ }^{(10)}$ recorded $86 \%$ targal perichondrium graft take. The cause of failure in cases in alter studies was not documented. In this study, 2 of the failed cases showed residual small perforation anterosuperiorly which were considered failure. Another cases developed graft necrosis due to upper respiratory tract infection 3 weeks postoperatively and last cases the cause was unknown.

It was found that there was improvement of hearing in subgroup IA ranging from 7.5-10dB with a mean of $9 \pm 1$ while in subgroup IIA; there was improvement of hearing ranging from 5-20 $\mathrm{dB}$ with a mean of $10 \pm 6.5$. There was no significant difference as regards improvement of hearing $(\mathrm{P}=0.67)$ (Table, 10). While in subgroup IB, the 2 successful cases showed improvement of hearing ranging of about $10 \mathrm{~dB}$ while in subgroup IIB; there was improvement of hearing ranging from 7.5-20 dB with a mean of $12 \pm 5 \mathrm{~dB}$. So, in large perforation, there was no significant difference between the studies groups $(\mathrm{P}=0.6)$ (Table, 10).

This was coincident with Dursun et al., (2008) $^{(2)}$ who found improvement of hearing in fat group by about $8.4 \pm 2.15 \mathrm{~dB}$ and in the perichondrium group by about $10.2 \pm 2.03 \mathrm{~dB}$ with no statistical significant difference in hearing improvement between the studied groups ( $\mathrm{P}>0.05)$.

In Singh et al. (2009) ${ }^{(11)}$ study, the improvement of hearing in perichondrium myringoplasty was $8.5 \mathrm{~dB}$ while in fat myringoplasty; it was $6.8 \mathrm{~dB}$ in tiny central tympanic membrane perforation.

In this study, the comparison between fat myringoplasty and perichondrium tympanoplasty in small tympanic membrane perforation with diameter $<4 \mathrm{~mm}$ showed no statistical significant difference as regard rate of graft take and postoperative improvement of hearing (Tables 4 and 12). While in large perforations $>4 \mathrm{~mm}$ there was significant difference in rate of graft take while postoperative improvement of hearing was not statistically different (Table 5 and 12).

As regards complication in group I (fat myringoplasty), there was no major complications and there was no possible complications of a 
classic tympanoplasty as facial nerve or chorda tympani injury, hearing loss. Atelectasia, myringitis, canal stenosis, scarring or adhesions in middle or external canal while in group II, there the disadvantages of longer healing period and dressing time, the potential to leave a visible scar and also two cases developed post-auricular wound infection which was controlled by frequent dressing and oral antibiotic.

In fat myringoplasty, there was limited need for postoperative ear care which is important in ear surgery. As there is virtually no manipulation of the middle ear structures, the risk of iatrogenic otological trauma is very low making it safe to perform.

Also, fat is easily obtained with little morbidity associated with harvesting it and the technique is simple to perform even in the hands of relatively inexperienced surgeons.

Those with hearing loss that cannot be explained by mere presence of the perforation should be offered a formal tympanoplasty where exploration of the ossicular chain can be done.

\section{CONCLUSION}

In conclusion, fat graft myringoplasty is a reliable technique not only for closure of punctiform tympanic membrane perforations, but also for closure of small and medium sized perforation.

Comparing the simplicity of the technique, the shorter time required for the procedure, and the less postoperative care, fat graft myringoplasty can be considered a good substitute fir perichondrium tympanoplasty for closure of small and medium sized perforations.

\section{REFERENCES}

1. Frootko, N. (2006): Reconstruction of the ear. Editors: Kerr AG, Booth JB. In: Scott-Brown's Otolaryngology, $5^{\text {th }}$ ed. London: Butterworth, 3:238-63.

2. Dursun, E. Gunger, R. and Dogru, S. (2008): Comparison of paper-patch, fat, and Perichondrium myringoplasty in repair of small tympanic membrane perforations. Otolaryngology-Head and Neck Surgery; 138:353-356.

3. Dabholkar, J.; Vora, K. and Sikdar, A. (2007): Comparative study of underlay tympanoplasty with temporalis fascia and targal Perichondrium. Indian. J. Otolaryngol. Head Neck Surgery, 59: 116-119.

4. Ringenberg, J. (1962): Fat graft tympanoplasty. Laryngoscope. 72: 188-192.

5. Mitchell, R. Pereira, K. and Lazer, R. (1997): Fat graft myringoplasty in children: A safe and successful day-stay procedure. J. Laryngol. Otol., 111: 106-8.

6. Chalishazar, U. (2005): Fat plug myringoplasty. Indian. J. Otolaryngol. Head Neck Surgery, 57 (1).

7. Deddness, A. Nuntz, H. and Lusk, R. (1993): Adipose myringoplasty in children. Laryngoscope. 103: 216-219.

8. Ayache, S. Braccini, F. and Facon, F. (2003): Adipose graft: An original option in myringoplasty. Otology and neurootology, 24: 158-164.

9. Konstantinidis, I. Malliari, H. and Taskiropoulou, E. (2010): Fat myringoplasty as an office- based procedure. Otorhinolaryngology, Head and Neck Surgery, 42: 25-28.

10. Reijnen, C. and Kuijpers, W. (1971): The healing pattern of the drum membrane. Acta. Otolaryngol. (Stockh.), 287: 1-74.

11. Singh, B. Sengupta, A. and Kumar, S. (2009): A comparative study of different graft materials used in myringoplasty. Indian. J. Otolaryngol. Head Neck Surgery, 61: 131-134. 


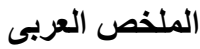

تؤدى ثقوب الاذن الى ضعف السمع و اتهابات لالذن الوسطى حتى لو كانت صغيره الحجم بالاضافى الى ان المريض لابد ان ير اعى احتياطات لمنع دخول الماء الى الاذن لاذن.

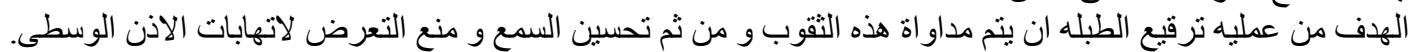

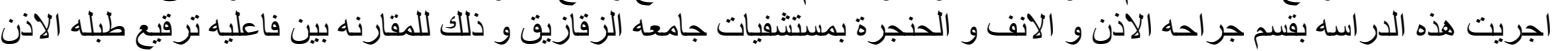

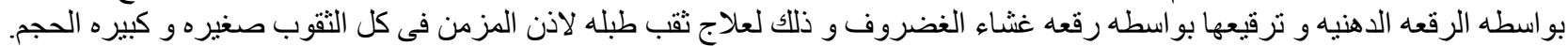

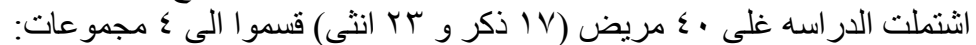

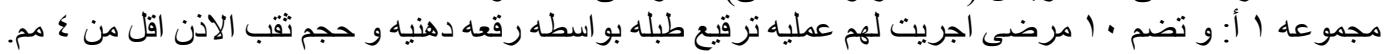

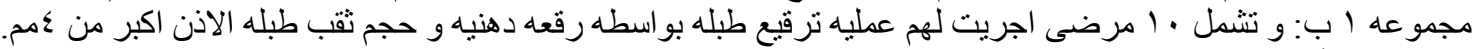

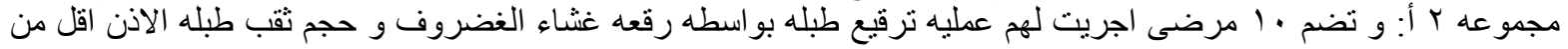
مجموعه r ب: و تضم . ا مرضى اجريت لهم عمليه ثرقيع طبله بو اسطه رقعه غثاء الغضروف و حجم ثقب طبله الاذن اكبر من كل المرضى تم فحصهم و تجهيز هم جيدا لاجر اء العمليه ومتابعتهم بالعيادات الخارجيه بقسم جر احه الاذن و الانف و الحنجرهو تم

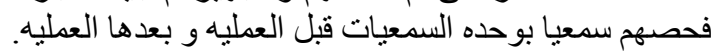

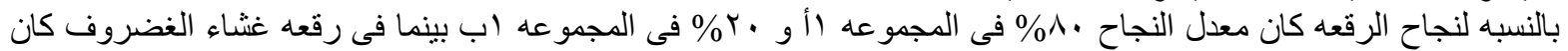

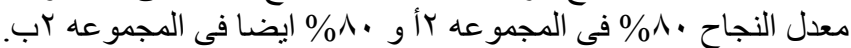

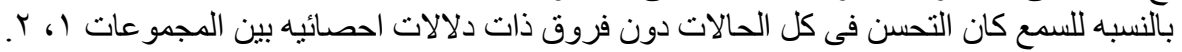

